BULLETIN Bulletin hispanique

HISPANIQUE Université Michel de Montaigne Bordeaux

$120-2$ | 2018

Varia

\title{
El tratamiento de la locución verbal en el DRAE
}

Le traitement de la locution verbale dans le Diccionario de la Real Academia española

The treatment of verbal locution in the "Diccionario de la Real Academia española"

\section{Mario García-Page Sánchez}

\section{(2) OpenEdition}

\section{Journals}

Edición electrónica

URL: https://journals.openedition.org/bulletinhispanique/7130

DOI: 10.4000/bulletinhispanique. 7130

ISSN: 1775-3821

Editor

Presses universitaires de Bordeaux

\section{Edición impresa}

Fecha de publicación: 10 diciembre 2018

Paginación: 615-626

ISBN: 979-10-300-0337-6

ISSN: 0007-4640

Referencia electrónica

Mario García-Page Sánchez, «El tratamiento de la locución verbal en el DRAE», Bulletin hispanique [En línea], 120-2 | 2018, Publicado el 02 enero 2022, consultado el 06 enero 2022. URL: http://

journals.openedition.org/bulletinhispanique/7130 ; DOI: https://doi.org/10.4000/bulletinhispanique. 7130 


\title{
El tratamiento de la locución verbal en el DRAE
}

\author{
Mario García-Page Sánchez \\ UNED
}

Le traitement de la locution verbale dans le Diccionario de la Real Academia española

L'objet de cette étude est de présenter le traitement dont la locution verbale a fait l'objet dans le $D R A E$ au long de son histoire. En comparant les différentes éditions, nous constatons que la description de la locution verbale n'a pas été uniforme et que, contrairement à ce qui se passe pour les autres types de locutions, la Real Academia a généralement évité l'utilisation du terme locution verbale en employant à sa place le terme «frase» [expression].

Mots-clés : locution verbale, expression, phraséologie, lexicographie.

El objeto principal de este estudio es dar cuenta del tratamiento que ha recibido la locución verbal en el $D R A E$ a lo largo de su historia. Con el cotejo de las distintas ediciones, comprobamos que la descripción de la locución verbal no ha sido uniforme y que, frente a lo que ocurre con las otras clases de locuciones, la Academia ha evitado normalmente el uso del término locución verbal, empleando a cambio el de frase.

Palabras Clave: locución verbal, frase, fraseología, lexicografía.

The treatment of verbal locution in the "Diccionario de la Real Academia española"

The main purpose of this paper is to present the treatment which the verbal locution underwent in the DRAE throughout its history. Comparing all the different editions, we notice that the description of verbal locutions was not uniform, and that, as opposed to how other types of locutions were treated, the $R A E$ generally avoided the use of the term verbal locution, using instead the term frase - expression.

Keywords: verbal locution, phrase, phraseology, lexicography. 


\section{INTRODUCCIÓN}

\section{El término locución en el DRAE}

El rastreo del término locución en las distintas ediciones del Diccionario de la lengua española de la Real Academia Española $(D R A E)^{1}$ de la primera de 1780 hasta la actual de 2014 (DLE), además del Diccionario de autoridades, nos revela que no es hasta la edición décima segunda de 1884 , en su tercera acepción, cuando aparece, en el artículo encabezado con el lema locución, una definición que -si bien incompleta- podría considerarse con justicia la primera de lo que hoy se entiende por locución entre los gramáticos y fraseólogos: «Conjunto de dos ó más palabras que no forman oración perfecta ó cabal; como, por ejemplo, los modos adverbiales». Si se coteja con la caracterización propuesta en 1950 por Julio Casares en su Introducción a la lexicografia moderna ${ }^{2}$, ampliamente asumida y utilizada por prácticamente todos los fraseólogos espańoles contemporáneos («combinación estable de dos o más términos, que funciona como elemento oracional y cuyo sentido unitario consabido no se justifica, sin más, como una suma del significado normal de los componentes»), o con la que, casi idéntica a esta, aparece en la edición decimonovena, de 1970 ( Gram. Combinación estable de dos o más palabras, que funciona como elemento oracional y cuyo sentido unitario no se justifica, sin más, como suma del significado normal de los componentes»), puede afirmarse que la de 1884 comparte con estas al menos dos rasgos fundamentales de las locuciones: la naturaleza pluriverbal (conjunto de dos o más palabras) y la estructura no oracional, si bien este segundo rasgo queda mejor precisado en la definición propuesta en la edición de 1970 al indicar que se trata de función, no de forma (es decir, la expresión, en su conjunto, equivale funcionalmente a un constituyente oracional, dígase más precisamente un sintagma con la función propia de un sustantivo, un adverbio, un adjetivo, etc.). Hasta el diccionario de 1884, las definiciones presentaban exclusivamente las acepciones de locución como sinónimo de modo de hablar y frase. A partir de esta edición hasta la décima octava de 1956, esa definición primeriza se mantiene inalterable, junto a las de modo de hablar y frase.

1. Todas las ediciones del DRAE, salvo la actual (Madrid, Espasa, 2014), han sido consultadas en línea a través del Nuevo tesoro lexicográfico de la lengua española (Madrid, RAE, 2001); de este modo eludimos la cita de la ficha bibliográfica de cada una. También se puede consultar así el Diccionario de autoridades, que es cómo se conoce el primer diccionario de la Real Academia Española una vez constituida esta en 1713, publicado en varios tomos (1726-1739), y que lleva por título Diccionario de la lengua castellana en que se explica el verdadero sentido de las voces, su naturaleza y calidad, con las phrases o modos de hablar, los proverbios o refranes, y otras cosas concernientes al uso de la lengua, Madrid, Imprenta de Francisco del Hierro y Herederos.

2. Julio Casares, Introducción a la lexicografía moderna, Madrid, CSIC, 1969, anejo LII de Revista de filología española. 
El cambio sustancial se va a producir, como decíamos, en la edición de 1970 -que calca casi literalmente la definición de Casares, antes señaladaya que enriquece la definición ańadiendo dos rasgos determinantes en la teoría fraseológica: el carácter fijo de la expresión («combinación estable») y el significado idiomático u opaco del conjunto («cuyo sentido unitario consabido no se justifica, sin más, como una suma del significado normal de los componentes»). Esta definición comprehensiva, compuesta de un haz de cuatro rasgos inseparables, se preserva casi inalterable (solo varía en las ediciones de 1984 y 1992, pues se añade la posibilidad de que la locución funcione como oración, además de como elemento oracional: «Combinación estable de dos o más palabras, que funciona como oración o como elemento oracional [...]» [cursiva nuestra]) hasta la edición vigésima segunda (2001), 4.a acepción -preservada, tal cual, en la edición vigésima tercera (2014), 4. a acepción-, que, a nuestro juicio, resulta más simple e incompleta $-\mathrm{y}$, por ende, menos precisa-al ser eliminado, injustificadamente, el cuarto rasgo, de orden semántico: «Gram. Combinación fija de varios vocablos que funciona como una determinada clase de palabra»: por ejemplo, los compuestos sintagmáticos-como molino de viento, mando a distancia, café bar u oso polar- se acomodarían perfectamente a tal caracterización. A ese cuarto rasgo parece aludir, no obstante, el DRAE (2001) en la 3. a acepción de locución-caracterización, si cabe, menos adecuada, ya que da cabida no solo a los compuestos, sino también a los sintagmas-, así como la Nueva gramática de la lengua española (Madrid, Espasa, 2009, \$1.5.2a); a partir de ahora $N G L E$ ), obra no lexicográfica, al afirmar que el significado de la locución no se obtiene «composicionalmente». La definición comprehensiva de la edición de 1970 parece recuperarse, con otra redacción, en la edición de 2014, 3. a acepción: «Gram. Grupo de palabras que funciona como una sola pieza léxica con un sentido unitario y cierto grado de fijación formal».

\section{La clasificación de las locuciones en el DRAE}

Resulta, cuando menos, extrańo que la Academia no establezca ninguna tipología de locuciones hasta la edición decimonovena (1970), y que, curiosamente, lo haga solo en el artículo lexicográfico dedicado al término locución. En la citada edición de 1884 (hasta la de 1956), se aludía tan solo a la clase adverbial llamándola -impropiamente- modo adverbial (véase supra).

Resulta también sorprendente que dicha tipología sea incompleta por cuanto solo da cuenta de las categorías adjetiva, adverbial, preposicional, conjuntiva e interjectiva, obviando deliberadamente la nominal, la pronominal y la verbal. Este hecho se confirma consultando tanto el Índice, donde se comprueba que, junto a la marca loc., aparecen explícitamente las correspondientes loc. adj., loc. $a d v$., loc. prepos., loc. conjunt. y loc. interj., como un registro cualquiera de estas clases de locuciones, donde se comprueba que figura la marca gramatical (así, por ejemplo, la expresión de tomo y lomo lleva la marca loc. adj.). 
El carácter incompleto de la clasificación se prolonga en las dos ediciones subsiguientes (1984 y 1992), si bien se amplía caprichosamente la nómina incluyendo la loc. conjunt. advers., la loc. conjunt. condic. y la loc. adv. interrog., lo que no deja de ser una incoherencia más, pues no solo no se trata de nuevas clases de locuciones, equiparables a las otras, sino que, además, habría que contemplar, de tener pertinencia la distinción, otras subclases de conjuntivas y adverbiales.

No sabemos explicar la razón de la ausencia de las locuciones nominal, pronominal y verbal, aunque podría aventurarse, respecto de la nominal, la falta de delimitación de esta en relación con los compuestos sintagmáticos (algo que se advierte modernamente incluso en la $N G L E$, en distintos lugares), $\mathrm{y}$, respecto de la pronominal, su absorción por la nominal, tal como han hecho algunos fraseólogos contemporáneos ${ }^{3}$, en la medida en que aquella funciona siempre como un nombre; por esa razón probablemente, la Academia, en la $N G L E(\$ 1.5 .2)$, tampoco la reconoce.

Es en la edición vigésima segunda (2001) donde, en el artículo correspondiente a la voz locución, la RAE ofrece una clasificación completa de las locuciones españolas, si bien no del todo adecuada pues, junto a las clásicas locución adjetiva, locución adverbial, locución preposicional o prepositiva, locución conjuntiva y locución interjectiva y las nuevas no recogidas en la edición décima novena de 1970 (locución sustantiva, locución pronominal, locución verbal), incluye una clase abiertamente espuria, completamente desencajada al carecer de correlato entre las categorías léxicas, la locución cuantificadora o intensificadora -asimilable a la locución elativa que han propuesto antes otros autores $\left.{ }^{4}\right)-$, clase que será oportunamente suprimida en el Diccionario esencial de la lengua española (Madrid, Espasa, 2006), así como en la NGLE (2009), donde también se prescinde de la locución pronominal, por lo que el número de clases de locuciones quedaría reducido a siete, frente a las nueve de la hasta entonces última edición del DRAE (2001) y las ocho del Diccionario esencial.

\section{LA LOCUCIÓN VERBAL EN EL DRAE}

\section{Tratamiento lexicográfico general}

La ausencia de la locución verbal en las distintas ediciones del diccionario es solo engañosa, pues el diccionario siempre ha registrado, en el lema correspondiente, las locuciones verbales españolas, solo que, en vez de describirlas con la marca loc. (loc. verbal), como el resto de clases, las describe,

3. Alberto Zuluaga, Introducción al estudio de las expresiones fijas, Frankfurt am Main-Bern, Verlag, Peter D. Lang, 1980, p. 151-155; Gloria Corpas Pastor, Manual de fraseología española, Madrid, Gredos, 1996, p. 96; Leonor Ruiz Gurillo, Las locuciones en el español actual, Madrid, Arco/Libros, 2001, p. 48; etc.

4. Alberto Zuluaga, op. cit., p. 146-149; Leonor Ruiz Gurillo, op. cit., p. 369-374. 
por lo común, como frases (ya en Autoridades) -usando el marbete $f$. (hasta la edición de 1822) o fr. (desde la edición de 1832 hasta la de 2001)- o, más raramente, como expresiones, identificadas con la abreviatura expr. (estas marcas gramaticales van acompañadas frecuentemente con las de coloq., fig., fam., e incluso vulg., sobre todo si entre los constituyentes de la locución hay una palabra tabú o malsonante: «andar en boca de alguien. fr. Ser objeto de lo que hable o diga», "caerse de culo. fr. coloq. Quedarse atónito y desconcertado ante algo inesperado", «lamer el culo a alguien. fr. vulg. malson. Adularlo servilmente para conseguir algo de él», etc.). Lo que ocurre es que, como hemos dicho, la clase locución verbal no consta, frente a lo que cabría esperar, en el repertorio de categorías locucionales de la edición décima novena de 1970, primera edición que establece una tipología (tampoco en la vigésima y vigésima primera, de 1984 y 1992, respectivamente), aunque sí en la de 2001. Esta sería la primera edición que determina específicamente la clase locución verbal, usando, además, el término locución verbal, que ilustra con el ejemplo caer en la cuenta. Lo que resulta ahora incongruente es que se siga recurriendo en el cuerpo de los artículos a la vieja marca fr. para describir las locuciones que genuinamente deben adscribirse a la clase verbal cuando ya ha sido utilizado explícitamente el término locución verbal. No existe, creemos, en ningún punto del DRAE, explicación alguna que justifique la resistencia de la Academia a emplear la marca loc. verbal en los artículos lexicográficos igual que hace para las otras locuciones -salvo, también curiosamente, la nominal (cabeza de chorlito, alma de cántaro, etc.)-. Tal inconsecuencia, al parecer, es subsanada en la edición vigésima tercera (2014), puesto que los registros ya no llevan la marca fr., sino loc. verb.; por ejemplo, buscar a alguien la boca: «loc. verb. Dar motivo, con lo que se dice o hace, para que alguien hable o diga lo que de otro modo callaría». Esta decisión puede venir impulsada por el deseo de la institución de uniformar el tratamiento dispensado a estas construcciones en la NGLE: en esta obra, en todo momento, se reconoce la clase locución verbal y se emplea el término locución verbal, y nunca el de frase o expresión.

En el índice de abreviaturas de la edición impresa de 2001 tampoco aparece la marca loc. verbal, pero esta ausencia es explicable coherentemente, pues tampoco figuran las marcas correspondientes a las restantes clases (loc. adj., loc. $a d v$., etc.), como sí se había hecho en la vigesimoprimera. En el índice tan solo consta la abreviatura loc., sin especificación ninguna.

Como es sabido, la Academia no discrimina, ni en el diccionario ni en la gramática, las clases locución clausal o proposicional (del tipo irsele el santo al cielo, calentársele la boca, lucirle el pelo, vérsele el plumero, subirsele los humos a la cabeza, caérsele el mundo encima, salirle el tiro por la culata, etc.) y oracional (del tipo no estar el horno para bollos, volver el agua por donde solía, volver las aguas a su cauce, juntarse el hambre con las ganas de comer, haber moros en la costa, no llegar la sangre al río, saltar el pájaro del nido, caer chuzos de punta, etc.), propuestas por algunos estudiosos 5 , a las que hubiera que asignar una marca. Conforme

5. Zoila Carneado Moré, «Algunas consideraciones sobre el caudal fraseológico del español 
a la tradición, la locución clausal o proposicional y la locución oracional son tratadas por la RAE, simple y llanamente, como locuciones verbales ${ }^{6}$, es decir, como frases, o, esporádicamente, como expresiones (hasta la última edición).

\section{Una curiosa excepción: la edición vigésimo primera del $D R A E(1992)$}

A lo largo de la historia lexicográfica de la Academia, esta se ha resistido, como hemos visto, a usar el término locución verbal e incluso a reconocerla como una clase más, junto a las restantes (más concretamente, la adjetiva, la adverbial, la conjuntiva, la prepositiva y la interjectiva), aunque hayan sido oportunamente recogidas, definidas e ilustradas en los artículos. El cambio de rumbo se produce en la vigésima tercera edición del $D R A E(D L E, 2014)$.

Ahora bien, aunque esta es la impresión generalizada, hay una excepción, la única que sepamos -que, no obstante, ha pasado casi desapercibida por los lingüistas, si bien no era el propósito principal de sus estudios ${ }^{7}$ : en la edición vigésima primera de 1992 aparecen, extrañamente, con la marca loc. verbal once registros: armarla, hacerla, liarlas, pagarla o pagarlas, pasarlo, pelárselas, picárselas, pirárselas, pintarla, jvuelve por otra!, cortarse solo. Como puede advertirse, tales registros, salvo dos (juelve por otra!, cortarse solo), tienen en común el ser verbos que llevan incorporado un complemento directo pronominal de naturaleza átona y referente desconocido: la, las o $l o$. La única restricción que podría aplicarse a esta excepción es el empleo esporádico e

\footnotetext{
hablado en Cuba», en Z. Carneado Moré y M. A. Tristá Pérez, Estudios de fraseología, La Habana, Academia de Ciencias de Cuba, 1983, p. 16-17; Gloria Corpas Pastor, op. cit., p. 109-110; Mario García-Page, "Fraseologismos oracionales», Contextos, n. ${ }^{\circ}$ 13/25-26, 1995, p. 79-92; "De los fines y confines de la fraseología», en J. M. González Calvo, J. Terrón González y J. C. Martín Camacho, Actas VII Jornadas de Metodología y Didáctica de la Lengua Española: Las Unidades Fraseológicas, Cáceres, Universidad de Extremadura, 2004, p. 70-79; «La locución oracional en español», en J. García-Medall, Fraseología e ironía. Descripción y contraste, Lugo, Axac, 2006, p. 71-83; e Introducción a la fraseología española. Estudio de las locuciones, Barcelona, Anthropos, 2008, p. 152-165.

6. También por la mayoría de los autores contemporáneos, como, p. ej., María Álvarez de la Granja, As locucions verbais galegas, Santiago de Compostela, Universidad de Santiago de Compostela, 2003, anejo 52 de Verba.

7. Zoila Carneado Moré, op. cit., p. 18-19; Alejandro Fajardo Aguirre, «Verbos y fraseología verbal con pronombres átonos en español», Lebende Sprache, n. ${ }^{\circ}$ 2, 1987, p. 74-75; Nicole Delbecque, «De la funcionalidad del clítico femenino plural en locuciones verbales», Revista de Filologia Románica, n. ${ }^{\circ}$ 24(1), 1997, p. 211-224; José Luis Mendívil Giró, Las palabras disgregadas. Sintaxis de las expresiones idiomáticas y los predicados complejos, Zaragoza, Prensas Universitarias de la Universidad de Zaragoza, 1999, p. 545-554; Mario García-Page, Introducción, op. cit., p. 340-342, y «Locuciones verbales con clítico en español del tipo dársela», Verba hispanica, n. ${ }^{\circ}$ 18, 2010, p. 135-145; cf., no obstante, María del Carmen González Orejón, «Las locuciones verbales en el DRAE», en M. Á. Esparza Torres, B. Fernández Salgado y H.-J. Niederehe, SEHL 2001, Estudios de historiografia lingüistica. Actas del III Congreso Internacional de la Sociedad Española de Historiografía Lingüistica, Hamburgo, Helmut Buske Verlag, 2002, t. II, p. 887892, y Mario García-Page, «En torno a la locución en el DRAE». Bulletin of Hispanic Studies, n. 90 (3), 2013, p. 251-260.
} 
inusitado, a lo largo de la historia del $D R A E$, de la marca loc. en algún registro, como es el caso de pasarlo en la edición decimoctava de 1956, que pervive hasta la edición vigésima de 1984; en esta misma edición (1984) y solo en ella, también lleva la marca loc. la locución pirárselas; algo que, más que error, cabría interpretar como indicio del alto grado de consciencia que se tenía del estatus de locución de dichas expresiones en el momento de describirlas durante la redacción del artículo lexicográfico.

La aludida solución de la edición de 1992, novedosa y excepcional, que podría interpretarse como un avance representativo al ganar uniformidad la técnica lexicográfica del diccionario académico y dotar de mayor concreción a las descripciones, si bien pone de relieve lo arbitrario -y desacertado- de la marca fr. aplicada habitualmente a secuencias que son genuinas locuciones verbales, no deja de resultar una incoherencia: no solo porque habría que extender dicha marca al corpus total de locuciones verbales recogidas en esa edición, sino también, con más razón si cabe, porque dicha marca habría de constar en todas aquellas construcciones similares de verbo + incremento pronominal, como liarla, diñarla, diñársela, pegársela, espicharla, cascarla, dársela, darla de o dársela de, echarla de, pasarlas moradas o negras, pasar las de Cain, verlas venir, cogerlas o cazarlas al vuelo, dársela con queso, coger o tomar las de Villadiego, etc. En efecto, con la consulta del diccionario, en la misma edición (1992), se comprueba que todas estas expresiones con clítico, cuando están registradas, son descritas, como era de esperar conforme a la práctica tradicional, como frases (por ejemplo, «pegársela a uno. fr. fam. Chasquearle, burlar su buena fe, confianza o fidelidad», «espicharla. fr. verbal. Morir, acabar la vida», etc.); lo que constituye, creemos, una incoherencia en relación con el tratamiento dispensado a los nueve registros antes citados. No solo la Academia, sino también algunos autores evitan el término locución para referirse a estas expresiones, como es el caso de Casares ${ }^{8}$, que las llama modismos.

El grado de arbitrariedad detectable en las descripciones lexicográficas del $D R A E$ resulta mayor cuando se comprueba que dos verbos con clítico la que forman parte del mismo artículo son tratados de manera diversa; así, bajo el lema diñar, la secuencia diñarla 'morir' no lleva ninguna marca, en tanto que sí la lleva diñársela: «diñársela a alguien. fr. Engañarle, burlarle». Asimismo, mientras que la locución hacerla es analizada como locución verbal («hacerla. loc. verbal con que se significa que uno faltó a lo que debía, a sus obligaciones o al concepto que se tenía de él»), su variante más extensa hacerla cerrada -que en esta edición aparece en lema aparte, no así en otras ediciones, como la primera o Autoridades (1734), donde se afirma que se usa "para dar mas viveza à la phrase»- es tratada como frase (lleva la marca $f$ r.); resulta, además, chocante que las marcas fig. y fam. que acompañan a esta otra (fr. fig. y fam.) sean suprimidas en aquella, cuando el grado de figuración o metaforicidad y familiaridad se nos antojan totalmente similares (en Autoridades 1734, por ejemplo, el tratamiento que se les da a ambas locuciones es, en este sentido,

8. Op. cit., p. 239-241. 
idéntico). Un caso semejante es el que representa el par pagarla o pagarlas y pagarla doble: en tanto las dos primeras se describen como locuciones verbales en la vigésima primera edición (1992), la última figura como frase: «pagarla, o pagarlas. loc. verbal fam. Sufrir el culpable su condigno castigo o la venganza de que se hizo más o menos merecedor. Muchas veces se usa en son de amenaza. Me las pagarás; me las has de pagar. II pagarla doble. fr. Recibir agravado el castigo que se merecía, por haberlo rehuido la primera vez».

No menos arbitrario es el diverso tratamiento que ha podido recibir una misma locución a lo largo del tiempo en distintas ediciones del diccionario. Así, por ejemplo, sabemos que la secuencia armarla ha sufrido continuos vaivenes: descrita primero (1780) como frase, aparece casi un siglo más tarde (1889) con la marca expr. fam., que es enseguida suprimida, solo diez años más tarde, en la edición de 1899, y sustituida de nuevo por la de fr., ahora complementada con la marca fam.; esta solución se mantiene hasta la edición vigésima segunda (1992), donde, como se ha indicado ya, la Academia opta por describirla más precisamente, igual que a los otros ocho registros citados, como locución verbal; si bien esta solución es efímera pues justo en ocasión de la siguiente edición, la de 2001, solo nueve años más tarde, la institución vuelve a tratarla como frase recuperando la vieja fórmula $f r$., aunque esta vez acompañada de la marca coloq. en vez de fam.

Son también varias las oscilaciones que ha experimentado el verbo pronominal picárselas, una locución bastante moderna ya que empieza a registrarse en el $D R A E$ a partir de la edición vigésima de 1984 (no consta siquiera en la de 1970, edición que comportó notables cambios): en esta edición la única marca que lleva es fig., sin determinar si es locución, frase o expresión; si bien se corrige inmediatamente en la versión manual de 1985, donde ya consta la marca fr., que va a ser sustituida por la de loc. verbal en la edición siguiente, la vigésima primera (1992), y restituida de nuevo en la edición vigésima segunda (2001). La juventud del registro lexicográfico de esta expresión puede tal vez explicarse por su origen americano conforme al criterio dialectal de la RAE.

También en este aspecto el diccionario académico ha sido vacilante pues, en las tres ediciones consecutivas donde hay constancia de su existencia, ha ido incorporando nuevas áreas de uso: así, este americanismo, que es primero descrito, en la edición de 1984 (así como en las versiones manuales de esta de 1985 y 1989), como originario en exclusiva de Argentina, y que figura ya con la marca diatópica correspondiente («picárselas. fig. Argent. Irse, por lo común rápidamente»), se enriquece como loc. verbal fig. Argent. y Perú en la edición de 1992, y como fr. Arg., Bol., Perú y Ur. en la de 2001. La participación en la redacción de la vigésima segunda edición del DRAE (2001) de todas las academias americanas de la lengua española va a suponer un notable aumento de registros de expresiones oriundas de estos países, que se acompańan con la marca dialectal correspondiente; así, por ejemplo, aparece por vez primera, en la edición de 2001, la locución pelársela -formalmente muy parecida a la 
registrada en la edición vigésima primera de 1992 pelárselas, pero de significado completamente distinto-, que se describe con la marca diatópica de su origen costarricense: "pelársela. fr. C. Rica. Quedar mal, fracasar». || 2. C. Rica. Llevarse un chasco».

Los dos registros de locuciones verbales sin clítico de la edición de 1992 también encarnan alguna suerte de arbitrariedad; así, jvuelve por otra!, a la que de ningún modo le conviene la etiqueta loc. verbal, consta ya en la edición siguiente (2001) como loc. interj., acorde con el tratamiento que reciben otras fórmulas del coloquio similares, si bien a veces se describen también como expr.; por su parte, cortarse solo pasa de ser, en la edición de 1992, una expresión propia de Uruguay con la marca loc. verbal y el significado "Apartarse de un grupo", a ser, en la edición de 2001, ya con la marca esperable fr., una expresión propia de Argentina y Uruguay con el significado «Hacer o decir algo al grupo al que pertenece».

Otro indicio de arbitrariedad observable tiene que ver con la ausencia consciente en el DRAE, incluso en las dos últimas ediciones, de numerosas locuciones verbales compuestas con un clítico. No nos referimos, claro está, a aquellas expresiones modernas de reciente creación, como liarla pard $a^{9}$, que solo a fuerza de su uso generalizado ingresarán algún día en el diccionario de la Academia, sino a ciertos registros, pertenecientes al acervo colectivo, que sí constan desde hace tiempo en otros diccionarios, como el Diccionario fraseológico documentado del español actual ${ }^{10}$ y el Diccionario fraseológico del español moderno ${ }^{11}$, así como en algunos estudios monográficos ${ }^{12}$. Según nuestras pesquisas, el conjunto más numeroso es el constituido por aquellas expresiones tildadas supuestamente como vulgares al contener palabras malsonantes o hacer referencia a un tabú (algún acto sexual, el órgano sexual masculino, etc.), como joderla, enchufársela o frotársela, algo en cierto modo esperable dado el criterio de decoro por que consuetudinariamente se rige la institución académica en la redacción de su obra lexicográfica. En este punto, resulta evidente la relevancia de este criterio cuando se cotejan dos variantes léxicas de una misma expresión: así, mientras registra, en la edición de 2001, las fórmulas pasarlas moradas, pasarlas negras y pasarlas canutas, no recoge la variante pasarlas putas, supuestamente por contener una palabra malsonante (si bien, sí consta la locución interjectiva oxte, puto). Pero, ciertamente, tampoco figuran otras muchas ya institucionalizadas sin esa marca, como palmarla y vérselas y deseárselas -aunque sí sus bases verbales sin el incremento pronominal, con el mismo significado, palmar, verse y desearse-, ni verlo negro o vérselas con

9. Véase, por ejemplo, Leonor Ruiz Gurillo, «Liarla parda o la convencionalización de una unidad fraseológica», Español actual, n. ${ }^{\circ}$ 91, 2009, p. 167-170.

10. Manuel Seco, Olimpia Andrés y Gabino Ramos, Diccionario fraseológico documentado del español actual. Locuciones y modismos españoles, Madrid, Aguilar, 2004.

11. Fernando Varela y Hugo Kubarth, Diccionario fraseológico del español moderno, Madrid, Gredos, 1994.

12. Como el citado Mario García-Page, «Locuciones verbales...» (cf. Alejandro Fajardo Aguirre, op. cit., p. 74-75). 
-aunque sí la variante verse las caras con-, no obstante, presentes en las versiones manuales de 1985 y 1989.

Por otro lado, a propósito de los ya comentados nueve registros de locuciones verbales con pronombre clítico de la edición de 1992 y en relación precisamente con el clítico, cabe hacer, al menos, tres observaciones que llegan a alcanzar carácter general en el corpus total de locuciones verbales con un incremento pronominal de esta naturaleza.

La primera, que el cambio flexivo $l a>$ las puede determinar un importante cambio semántico (se trata, entonces, de locuciones distintas) o no determinarlo (se trata, entonces, de variantes morfológicas) ${ }^{13}$. La primera situación es magníficamente ilustrada con el par liarla / liarlas, las dos presentes en la edición de 1992: la primera locución, polisémica, significa bien «meter la pata», bien «organizar, armar un lío», y la segunda, también polisémica, significa bien «huir», bien «morir»; la segunda situación es la representada por el par pagarla I pagarlas, también las dos presentes en la edición de 1992 (la segunda, con las, dispone, a su vez, de la variante extensa pagarlas todas juntas): «sufrir el culpable su condigno castigo o la venganza de que se hizo más o menos merecedor».

La segunda observación es que la conversión de un verbo transitivo con clítico en un verbo pronominal gracias a la incorporación de un se en la base puede determinar un cambio de significado (se trata, entonces, de locuciones distintas) o no determinarlo (se trata, entonces, de variantes gramaticales) ${ }^{14}$. La primera situación no puede ilustrarse con ningún ejemplo de los nueve registros de la edición de 1992, pero sí con el par diñarla / diñársela, que aparecen en la edición de 2001: la primera locución significa «morir» y la segunda, «engañarle, burlarle»; la segunda situación está representada por el par liarlas / liárselas, ya comentado, que en la edición de 1984 figuran como variantes, aunque la segunda expresión es suprimida en la edición de 1992.

La tercera observación es que algunas locuciones con pronombre átono de complemento directo sufren un proceso de polisemización o ampliación semántica, como ilustra a la perfección la expresión armarla, que, de significar, en la edición de 1780 hasta la de 1852, solo "hacer trampas (en el juego de naipes)», pasa a significar también, en la edición de 1869 hasta la actual, "promover riña o alboroto». Asimismo, la locución liarlas, que, desde el Diccionario de autoridades, significa exclusivamente «huir», amplía su significado al de «morir» desde la edición de 1803 hasta la actual. Puede ocurrir que el cambio semántico no sea tal, sino más bien un cambio de decisión más o menos caprichosa de la institución: el desdoblamiento en dos acepciones

13. Véase Mario García-Page, «Variantes morfológicas y unidades fraseológicas», Paremia, 8 , p. 225-230, Introducción..., op. cit., p. 340-342, y «Locuciones verbales...», op. cit., p. 138-139.

14. Este fenómeno ha sido tratado en Mario García-Page, «La función diacrítica de se en las locuciones verbales», en P. Barros García, G. Águila Escobar y E. T. Montoro del Arco, Estudios lingüisticos, literarios e históricos. Homenaje a Juan Martínez Marín, Granada, Universidad de Granada, 2007, p. 205-213; «De lo superfluo del dativo superfluo en las locuciones», Lingüística española actual, n. ${ }^{\circ}$ 29, 2, 2007, p. 209-231; Introducción..., op. cit., p. 150-152; y «Locuciones verbales...», op. cit., p. 138. 
distintas de lo que previamente constituía una sola definición; es lo que parece ocurrir con la locución pelárselas: en tanto en la edición de 1970 (ya en la de 1884) se define como «expr. fig. y fam. con que se da a entender que uno apetece o ejecuta una cosa con vehemencia, actividad o eficacia», en la edición de 1992 figura como «loc. verbal. fig. y fam. Apetecer alguien con vehemencia una cosa. SE LAS PELA por figurar. \| fig. y fam. Ejecutar alguna cosa con vehemencia, actividad o eficacia. Corre que SE LAS PELA...».

\section{Conclusiones}

Del estudio llevado a cabo en las páginas precedentes, pueden extraerse las siguientes conclusiones:

a) El tratamiento gramatical dispensado por la Academia a las locuciones en general y a la locución verbal en particular en su obra lexicográfica a lo largo de la historia no ha sido uniforme.

b) La primera definición, incompleta e insuficiente, de locución aparece tardíamente, en la edición de 1884, aunque la más completa es de 1970 (edición decimonovena).

c) Es en esta edición de 1970 donde por vez primera se propone una clasificación de las locuciones españolas en el artículo encabezado con el lema locución. Esta clasificación es incompleta porque solo da cuenta de cinco clases (adjetiva, adverbial, prepositiva, conjuntiva e interjectiva); se completa en la vigésima segunda (2001), en el mismo artículo, con la incorporación de las tres que faltaban (nominal, pronominal y verbal), si bien se añade irregularmente otra (intensificadora o cuantificadora), que será luego suprimida.

d) Existe desde el primer momento fuerte resistencia a usar el término locución verbal, y, en consecuencia, la marca loc. verbal en la definición de las unidades, que ni siquiera aparece en la primera edición impresa del siglo XXI (2001). Las locuciones verbales son descritas, desde Autoridades, como frases y, más raramente, como expresiones. Es en la edición vigésima tercera (2014) donde por vez primera la definición de las locuciones verbales lleva, coherentemente, la marca loc. verb.

e) En este sentido, la edición vigésima primera de 1992 constituye, aunque limitada, una excepción, pues en ella constan once registros que llevan la marca loc. verbal, de los que nueve tienen la particularidad de ser locuciones compuestas de verbo transitivo, a veces pronominal, y un pronombre clítico de objeto directo (la, las, lo): armarla, hacerla, liarlas, pagarla o pagarlas, pasarlo, pelárselas, picárselas, pirárselas, pintarla; la marca loc. verbal será inmediatamente reemplazada, en la edición siguiente, por la habitual fr. Lo contradictorio es que el resto de las locuciones verbales existentes, incluidas aquellas de similar composición, son tratadas como frases. 
